\title{
Assesment of Alkali Resistance of Basalt Used as Concrete Aggregates
}

\author{
${ }^{1}$ Aref M. al-Swaidani, ${ }^{2}$ Mohammad K. Baddoura, ${ }^{3}$ Samira D. Aliyan, ${ }^{4}$ Walid Choeb \\ ${ }^{1}$ Arab International University, Damascus, Syria, Faculty of Architecture \\ ${ }^{2}$ Syrian Code Committee, Order of the Syrian Engineers, Damascus, Syria \\ ${ }^{3}$ Syrian Arab Organization for Standardization and Metrology, Damascus, Syria \\ ${ }^{4}$ Order of Syrian Engineers, As-Swaida'a, Syria \\ e-mail: aydlswaidani@yahoo.fr, a-swaidani@aiu.edu.sy
}

\begin{abstract}
The objective of this paper is to report a part of an ongoing research on the influence of using crushed basalt as aggregates on one of durability-related properties of concrete (i.e. alkali-silica reaction which is the most common form of Alkali-Aggregate Reaction). Alkali resistance has been assessed through several methods specified in the American Standards. Results of petrographic examination, chemical test (ASTM C289) and accelerated mortar bar test (ASTM C1260) have particularly been reported. In addition, the weight change and compressive strength of 28 days cured concrete containing basaltic aggregates were also reported after 90 days of exposure to $10 \% \mathrm{NaOH}$ solution. Dolomite aggregate were used in the latter test for comparison. The experimental results revealed that basaltic rocks quarried from As-Swaida'a region were suitable for production of aggregates for concrete. According to the test results, the studied basalt aggregates can be classified as innocuous with regard to alkali-silica reaction. Further, the $10 \%$ sodium hydroxide attack did not affect the compressive strength of concrete.
\end{abstract}

Key words: alkali resistance, basalt aggregate, durability, alkali-silica reaction

\section{Introduction}

Basalt is the most common type of extrusive igneous rock and the most common rock type at the earth's surface [1]. Basaltic rocks are used extensively as engineering materials including aggregates for Portland cement concrete and asphaltic concrete [2]. Few published test results on the properties of basaltic rock aggregates indicate that the use of crushed basalt aggregate can significantly affect the properties of concrete [3-5]. Syria is very rich in Basaltic rocks. Due to some concerns, use of basalts as aggregate material is very limited in Syria. One of the most important concerns is the risk of the alkali attack by the cement paste which leads to what is commonly known as alkali-aggregate reaction. For this reason, a particular attention was recently given to the evaluation and the potential exploitation of basalt which is broadly 
abundant in Syria. More than $30000 \mathrm{~km}^{2}$ of the country is covered by tertiary and quaternaryage volcanic rocks [6], among which basalt occupies important volume with estimated reserves of about several billion tonnes [7]. There are few geological investigations on these volcanic rocks. However, their potential use as concrete aggregate is still not well established.

Concrete is highly alkaline with $\mathrm{pH}$ values normally above 12.5 , and is easily attacked by acid solutions [8]. Siliceous aggregates such as basalt are generally acid resistant [9-11]. However, these may be susceptible to attack by alkalis, depending on the nature of the silica minerals [11]. Alkali-silica reaction, which is the most common form of alkali-aggregate reaction, is a reaction between the hydroxyl ions in the pore solution of a concrete and certain forms of silica occasionally present in significant quantities in the aggregate, the most reactive forms of silica being the most disordered forms, namely, opaline silica and volcanic glass [12]. As a result an alkali-silica gel is formed. This gel may imbibe water and swell, sometimes causing disruption of the concrete [13].

Although there are a lot of studies on using basalt rocks as concrete aggregate, no detailed research was conducted in the past to investigate the potential use of basalt as concrete aggregate in Syria. This study is part of the first detailed research in Syria to investigate the potential utilization of basalt as concrete aggregate, and its effects on the performance of concrete. The objective of this paper is to report a part of this ongoing research on the influence of crushed basalt as aggregates on the alkali resistance of concrete. Alkali resistance has been investigated through several methods specified in ASTM. Results of petrographic examination, chemical test [ASTM 289] and accelerated mortar bar test [ASTM 1260] have particularly been reported. In addition, the weight change and compressive strength of 28 days cured concrete containing basaltic aggregates were also reported after 90 days of exposure to $10 \% \mathrm{NaOH}$ solution. Dolomitic aggregates were employed in the latter test for comparison.

The study is of particular importance not only for the country but also for other areas of similar geology, e.g. Harrat Al-Shaam, a volcanic field covering a total area of some 45000 $\mathrm{km}^{2}$, third of which is located in the country. The rest is covering parts from Jordan and Saudia Arabia, as shown in Fig.1.

\section{Materials and methods}

\subsection{Materials}

The basalt used in the experiments was collected from two different sites in As-Swaida'a region, about $100 \mathrm{~km}$ southeast of Damascus, as shown in the Fig.1. Crushed dolomite extracted from Hassia region, about $120 \mathrm{~km}$ north of Damascus, was also used for comparison in the exposure to $10 \% \mathrm{NaOH}$ solution. The chemical analysis and some requirements of the basalt samples and the dolomite sample are summarized in Table 1 and Table 2, respectively. The chemical analysis was carried out by means of X-Ray fluorescence. The cement used in the experiments was obtained from Adra Cement Plant, Damascus, Syria. Chemical analysis of cement is shown in Tab.1.

Three concrete mixes were prepared. The first and second mixes were prepared by using crushed basalt aggregates while the third by crushed dolomite aggregate. The grading of 
aggregate mixtures was kept nearly close to fuller's curve for all concrete mixes. Their quantities in $1 \mathrm{~m}^{3}$ concrete mix based on oven-dry condition are summarized in Table 3. All concrete mixes were designed to have a water-cement ratio of 0.6 and a slump of $100 \pm 20 \mathrm{~mm}$. Concrete cubes $(150 \mathrm{~mm})$ were cast for each of aggregate type and curing age for the determination of compressive strength. Concrete cylinders $(100 \mathrm{~mm} \times 200 \mathrm{~mm})$ for each of aggregate type were cast, for investigating the alkali resistance of concrete mixes. Two slice of $100 \mathrm{~mm}$ in diameter and $50 \mathrm{~mm}$ in thickness were cut from the middle portion of each concrete cylinder specimens $(100 \times 200 \mathrm{~mm})$. They were used for immersion in the $10 \%$ $\mathrm{NaOH}$ solution.

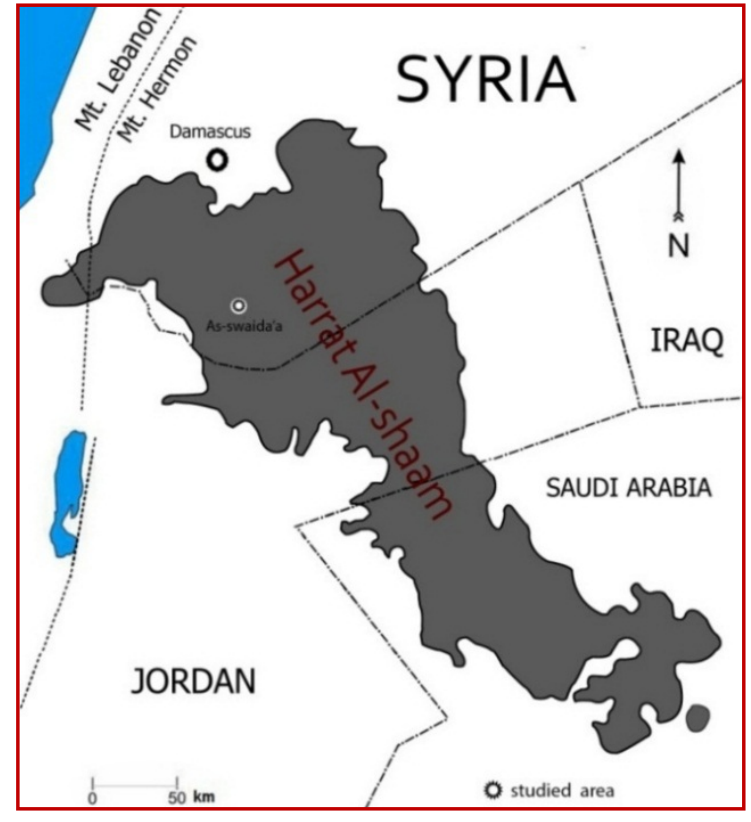

a. Map of Harrat Al-Shaam and the studied area (Al-Swaida'a governance)

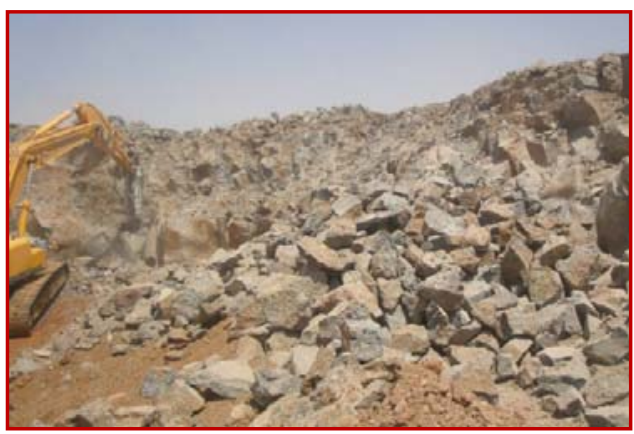

c. The Ariqa basalt quarry.

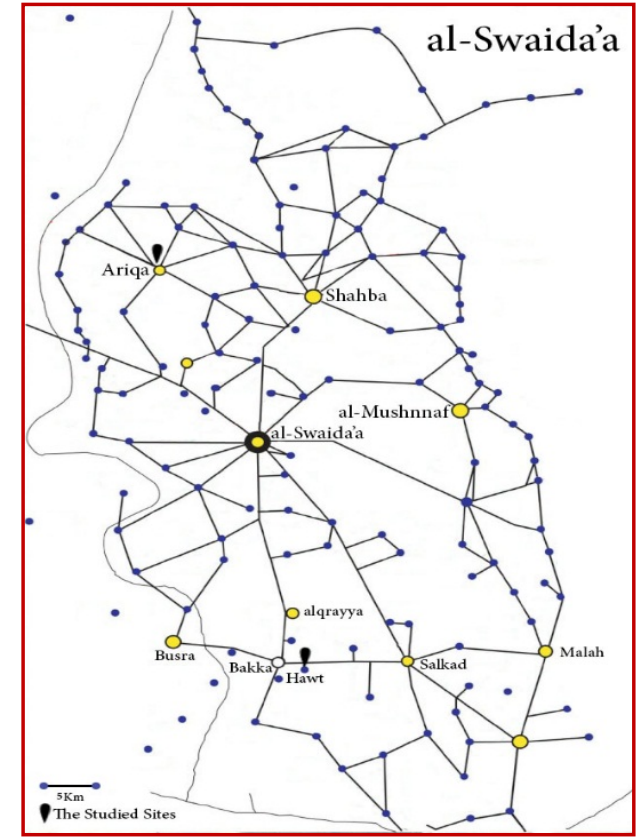

b. Map of the studied sites in Al-Swaida'a

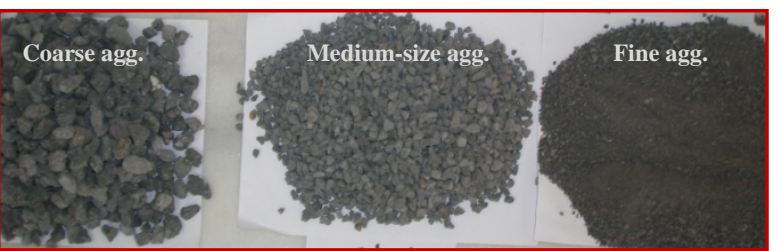

Figure 1: Map of Harrat Al-Shaam\& the studied sites, photo of Ariqa quarry and basalt aggregates 


\subsection{Methods}

The compressive strength development was determined on $150 \mathrm{~mm}$ cubic concrete specimens in accordance with ISO 4012, at ages of 2, 3, 7, 28, 90 days. The alkali resistance was assessed though different ways specified in the American standards. The first of these was done through the petrographic analysis. The second was the chemical test conducted in accordance with ASTM C289. The potential reactivity of the investigated aggregates was assessed from the analytical results by reference to a graph given in the method which correlates test results with the known field performance of a number of aggregates. Mortar bar length measurements, as carried out in accordance with ASTM C1260, are recommended to confirm chemical test results. This test is one of the most commonly used tests worldwide at present [11]. The method involves monitoring expansion of mortar bars containing the test aggregate and immersed in a $1 \mathrm{M} \mathrm{NaOH}$ at $80^{\circ} \mathrm{C}$.

Table 1: Chemical composition of the used materials

\begin{tabular}{lllll}
\hline \multirow{2}{*}{$\begin{array}{l}\text { Chemical composition (by } \\
\text { mass, \%) }\end{array}$} & Materials & & & \\
\cline { 2 - 5 } & Hawt' basalt & Ariqa' basalt & Dolomite & Cement \\
\hline $\mathrm{SiO}_{2}$ & 45.76 & 45.97 & 0.42 & 20.43 \\
\hline $\mathrm{Al}_{2} \mathrm{O}_{3}$ & 16.87 & 16.55 & 0.38 & 5.86 \\
\hline $\mathrm{Fe}_{2} \mathrm{O}_{3}$ & 14.39 & 13.98 & 0.10 & 3.20 \\
\hline $\mathrm{CaO}$ & 8.93 & 9.14 & 31.40 & 61.69 \\
\hline $\mathrm{MgO}$ & 6.61 & 6.31 & 20.46 & 2.31 \\
\hline $\mathrm{Na} 2 \mathrm{O}$ & 2.64 & 2.69 & 0.06 & 0.81 \\
\hline $\mathrm{K}_{2} \mathrm{O}$ & 1.05 & 1.16 & 0.30 & 0.24 \\
\hline $\mathrm{TiO}_{2}$ & 2.53 & 2.49 & 0.18 & 0.25 \\
\hline $\mathrm{Mn}_{2} \mathrm{O}_{3}$ & 0.16 & 0.15 & - & - \\
\hline $\mathrm{Cl}^{-}$ & 0.01 & 0.01 & 0.021 & 0.05 \\
\hline $\mathrm{SO}_{3}$ & - & - & - & 2.30 \\
\hline $\mathrm{Loss}_{3}$ on ignition & 1.1 & 1.1 & 46.48 & 2.29 \\
\hline Insoluble residue & - & - & - & 0.59 \\
\hline & & & & \\
\hline
\end{tabular}

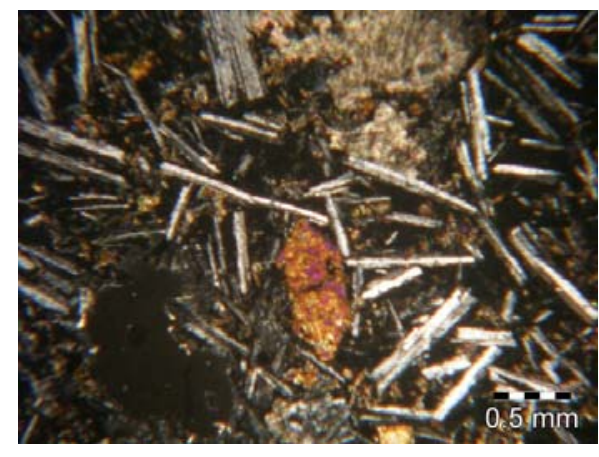

a.

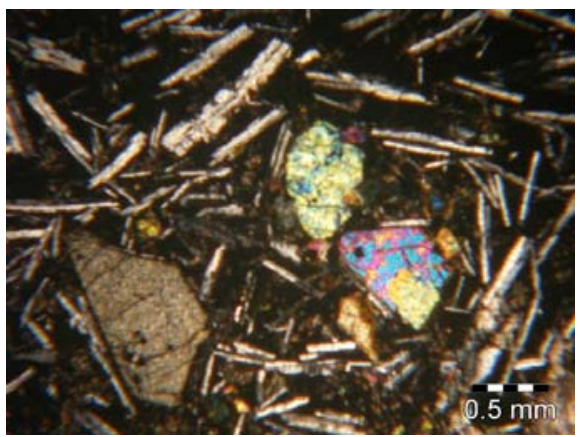

b.

Figure 2: Thin sections of the studied basalt. a). Microphenocryst of Olivine, Clinopyrosene and elongated plagioclase in volcanic glass matrix of Hawt basalt. b). Microphenocrysts of Olivine and elongated plagioclase in volcanic glass matrix of Ariqa basalt. 
Table 2: Ingredients of the concrete mixes

\begin{tabular}{lllllll}
\hline Mix type & $\begin{array}{l}\text { Fine } \\
\text { aggregate } \\
(\mathrm{kg})\end{array}$ & $\begin{array}{l}\text { Medium-size } \\
\text { aggregate } \\
(\mathrm{kg})\end{array}$ & $\begin{array}{l}\text { Coarse } \\
\text { aggregate } \\
(\mathrm{kg})\end{array}$ & Cement $(\mathrm{kg})$ & Water $(\mathrm{kg})$ & $\begin{array}{l}\text { Total } \\
\text { weight } \\
\left(\mathrm{kg} / \mathrm{m}^{3}\right)\end{array}$ \\
\hline $\begin{array}{l}\text { Basalt-based } \\
\text { concrete (BBC) }\end{array}$ & Ariqt: 843 & 334 & 667 & 350 & 210 & 2404 \\
\hline $\begin{array}{l}\text { Dolomite-based } \\
\text { concrete (DBC) }\end{array}$ & 675 & 336 & 670 & 350 & 210 & 2406 \\
\hline
\end{tabular}

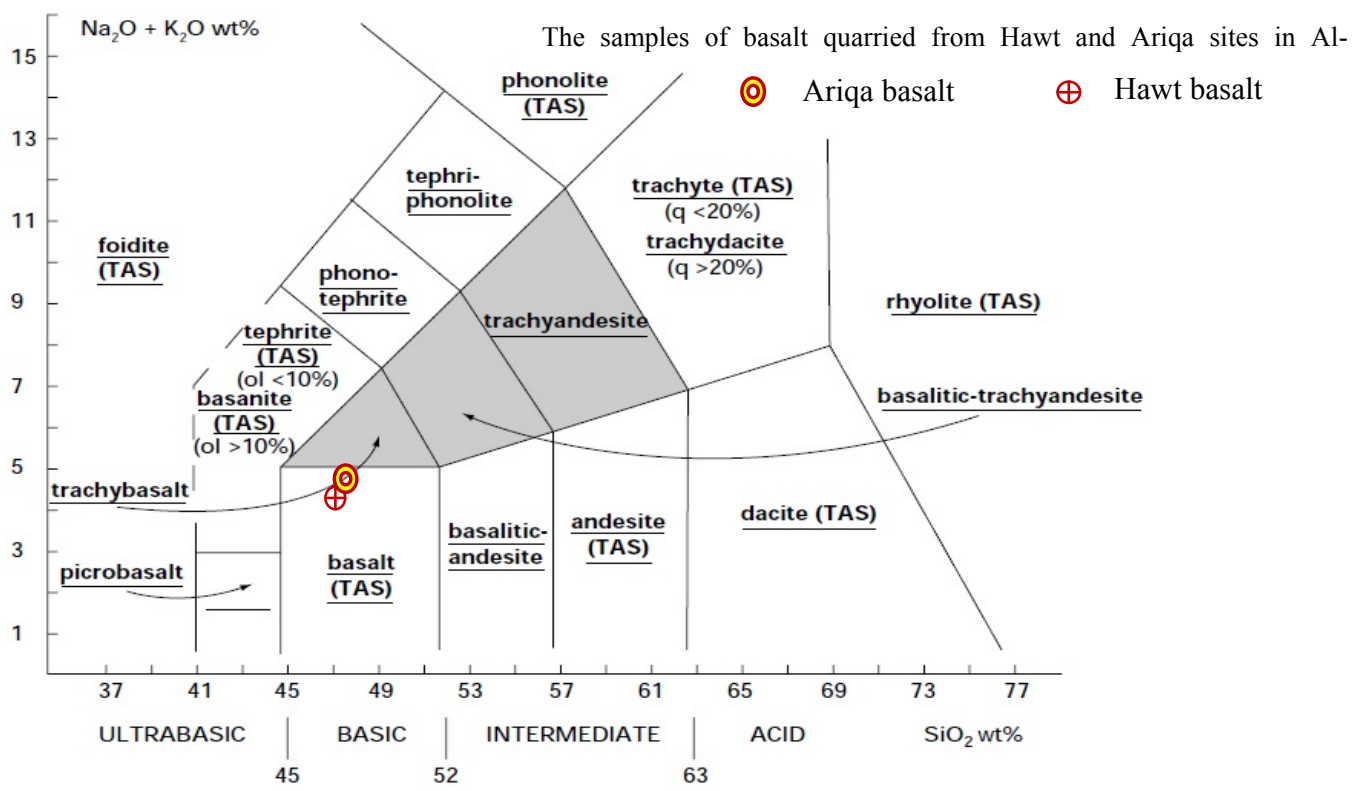

Figure3: Classification of the basalt samples quarried from As-Swaida according to Le Maitre et al. [18]

In addition, ASTM C-267 was also employed to assess the alkali resistance of basalt-based concrete specimens. The total alkalinity $\left(\mathrm{Na}_{2} \mathrm{O}+0.658 \mathrm{~K}_{2} \mathrm{O}\right)$ of the cement used for making concrete is about $1 \%$. After $2,7,14,28,56,90$ days of immersion in $10 \% \mathrm{NaOH}$ solution, each specimen was removed from the baths, brushed with a soft nylon brush, and rinsed in distilled water. The specimen was then dried and weighed. The alkali resistance was evaluated through the visual inspection of the tested specimens and the measurement of the weight change of the specimens determined as follows: Weight change $(\%)=\mathrm{W}_{\mathrm{o}}-\mathrm{W}_{\mathrm{i}} / \mathrm{W}_{\mathrm{o}}$; Where $\mathrm{W}_{\mathrm{o}}$ is the weight (in grams) of the specimens before immersion and $\mathrm{W}_{\mathrm{i}}$ is the weight (in grams) of cleaned specimens after i-day of immersion (i: 2, 7, 14, 28, 56, 90 days). After weighing, each slice was then returned to the appropriate solution. After 90 days of immersion, all specimens were photographed and tested for the determination of compressive strength. The evaluated concrete specimens were cured for 28 days. The average value for four specimens was considered for assessment. Crushed dolomite was used for comparison. 
Table 3: Some characteristics of crushed basalts and dolomite with some typical acceptance limits

\begin{tabular}{|c|c|c|c|c|c|c|c|}
\hline \multirow[b]{2}{*}{ Characteristic } & \multicolumn{3}{|c|}{ Crushed basalt aggregates } & \multicolumn{3}{|c|}{ Crushed dolomite aggregates } & \multirow{2}{*}{$\begin{array}{l}\text { Acceptance } \\
\text { limits }\end{array}$} \\
\hline & Fine & $\begin{array}{l}\text { Medium } \\
\text {-size }\end{array}$ & coarse & Fine & $\begin{array}{l}\text { Medium } \\
\text { - size }\end{array}$ & coarse & \\
\hline Specific Gravity & $\begin{array}{l}\text { Hawt: } 2.72 \\
\text { Ariqa: } 2.71\end{array}$ & $\begin{array}{l}2.78 \\
2.79\end{array}$ & $\begin{array}{l}2.78 \\
2.79\end{array}$ & 2.70 & 2.71 & 2.71 & $\begin{array}{ll}>2.6 & {[\mathrm{BS}} \\
812: 1975] & \end{array}$ \\
\hline Absorption (\%) & $\begin{array}{l}\text { Hawt:1.56 } \\
\text { Ariqa:1.61 }\end{array}$ & $\begin{array}{l}1.33 \\
1.41\end{array}$ & $\begin{array}{l}1.33 \\
1.41\end{array}$ & 1.50 & 1.45 & 1.45 & $\begin{array}{l}<2 \quad \text { [ASTM } \\
33: 1986] \\
<2.5 \quad \text { CASTM } \\
\text { C127] } \\
<3 \quad \text { [BS } \\
8007: 1987] \\
\end{array}$ \\
\hline $\begin{array}{l}\text { Sand Equivalent } \\
(\%) \text { [ASTM D2419] }\end{array}$ & $\begin{array}{l}\text { Hawt: } 87 \\
\text { Ariqa: } 85\end{array}$ & & & 75 & & & $>70 \%[19]$ \\
\hline Los Angeles (\%) & & & $\begin{array}{l}\text { Hawt: } 17.0 \\
3 \\
\text { Ariqa: } \\
17.54\end{array}$ & & & 22.15 & $\begin{array}{lr}<45 \quad(500 \\
\text { cycles) [ASTM } \\
\text { C 33:1986] } \\
<25 \% \text { for } \\
\text { wearing } \\
\text { surfaces } \\
\text { [ASTM C131] } \\
\text { [A }\end{array}$ \\
\hline $\begin{array}{l}\mathrm{Na}_{2} \mathrm{SO}_{4} \\
\text { Soundness } \\
\text { [ASTM C88] }\end{array}$ & & & $\begin{array}{l}\text { Hawt: } \\
0.394 \\
\text { Ariqa: } \\
0.419\end{array}$ & & & 0.464 & $\begin{array}{l}<12 \text { (coarse } \\
\text { aggregate) after } \\
5 \text { cycles in } \\
\mathrm{Na}_{2} \mathrm{SO}_{4}[\mathrm{ASTM} \\
\mathrm{C} 33 ; \text { ASTM } \\
\mathrm{C} 88]\end{array}$ \\
\hline $\begin{array}{l}\text { Thermal } \\
\text { conductivity } \\
(\mathrm{W} / \mathrm{m} . \mathrm{k}) \quad \text { (rock } \\
\text { sample: } \\
150 \times 150 \times 50 \mathrm{~mm})\end{array}$ & $\begin{array}{l}\text { Hawt: } 1.81 \\
\text { Ariqa: } 1.87\end{array}$ & & & 2.64 & & & \\
\hline $\begin{array}{l}\text { Particle finer than } \\
75 \mu \mathrm{m}(\%)\end{array}$ & $\begin{array}{l}\text { Hawt: } 3.50 \\
\text { Ariqa: } 3.86\end{array}$ & & & 6.47 & & & $\begin{array}{l}<5 \% \text { [ASTM C } \\
33]\end{array}$ \\
\hline $\begin{array}{l}\text { Chloride content } \\
\left(\mathrm{Cl}^{-}\right)\end{array}$ & & & $\leq 0.01$ & & & 0.021 & $\begin{array}{l}<0.05 \% \\
882: 1992]\end{array} \quad[\mathrm{BS}$ \\
\hline Sulfate content (SO & & & - & & - & & $\begin{array}{l}<0.4 \% \\
812: 118]\end{array} \quad[\mathrm{BS}$ \\
\hline
\end{tabular}

\section{Results and discussion}

\subsection{Properties of basalt}

As seen from Tab.3 and Fig.3, crushed basalt rock is classified as basic basalt and can be considered as suitable material for use as aggregate. It satisfied the standards requirements for such a material by having a specific gravity of more than 2.6, water absorption (\%) of less than $2 \%$, a sand equivalent of more than $70 \%$, a Los Angeles value (\%) of less than 45 and $\mathrm{Na}_{2} \mathrm{SO}_{4}$ soundness of less than 12 for coarse aggregates, respectively. In addition, the chemical composition of basalt aggregates, as shown in Tab.1, is also in conformity with the standards requirements. Their contents of $\mathrm{Cl}^{-}$and $\mathrm{SO}_{3}$ are less than $0.05 \%$ and $0.2 \%$, respectively. 


\subsection{Compressive strength of concretes}

The development of the compressive strength with age of basalt-based concrete (BBC)-and dolomite-based concrete (DBC) is shown in Fig.4. As expected, the compressive strength of the concrete increases with curing time with a high rate of strength gain at early ages which gradually decreases at longer ages. BBC specimens have higher compressive strengths beyond 7 days when compared with DBC ones. The relatively higher compressive strength of $\mathrm{DBC}$ at early ages may be due to some interfacial chemical reactions which may improve the bond strength $[4,30]$. In return, the higher compressive strength of BBC beyond 7 days could not be easily explained in the normal strength concrete. Tasong et al. [3] indicated to the higher apparent interfacial bond strength in basalt when compared with dolomite. Furthermore, according to authors, crushed basalt is more angular and rougher than dolomite. This may make the interfacial transition zone (ITZ) when using basalt more compacted, and thereby the bond between the hydrated cement and aggregate becomes stronger.

\subsection{Assessment of alkali resistance}

The petrographic study could be very useful for determining the potential reactivity of aggregates. The petrographic examination of the two investigated aggregates showed that olivine, clinopyroxene, plagioclase and volcanic glass were the main constituents of both of them. Their percentages, according to an optical estimate, were approximately $20 \%, 20 \%$, $30 \%$ and $20 \%$, respectively. Traces of clay minerals were also observed. Fig. 2 shows thin sections of the used basalt. Wakizaka [15]implied that volcanic rocks including volcanic glass are susceptible to alkali-silica reaction. From the point of alkali-silica reactivity, volcanic glass existing in the samples could be important. However, basalts are typically of low reactivity, but where petrographic identified glass, ASR reactivity could be higher. The chemical nature of the glass also plays a role, with acidic glasses (those richer in $\mathrm{SiO} 2$ ) being typically more reactive [16, 17]. According to Le Maitre et al.[18], both of basalt samples can be classified as basic basalt, as illustrated in Fig.3. Further, the chemical analysis of the basalt (see Tab.1) demonstrated that the basalt had around $45 \% \mathrm{SiO}_{2}$. According to Katayama et al. [20] the basalt could be unreactive when its silica content is less than $50 \%$.

The reduction in the alkalinity of a normal solution of $\mathrm{NaOH}$ when placed in contact with pulverized aggregate at $80{ }^{\circ} \mathrm{C}$ is determined, and the amount of dissolved silica is measured. The Results for both investigated aggregates are plotted in Fig 5. These results were checked against calibration curve in accordance with ASTM 289 (2001). The plotted test results fall to the left of the boundary line in Fig.5 indicating no potentially deleterious reaction. As a result, both aggregates are classified according this calibration curve as innocuous.

Fig. 6 shows the change of dilatation in length against time of both aggregates used and a view of the tested mortar bars placed in the container. According to ASTM 1260 (2001), the percentage of dilatation in length for 16 days should be under $0.10 \%$. Expansions of less than $0.10 \%$ at 16 days after casting are indicative of innocuous behavior in most cases. Davies and Oberholster [21] and Hooton and Rogers [22] also indicated that expansions of less than $0.10 \%$ at two weeks after casting are indicative of innocuous behavior in most cases. As shown in Fig.6, both of the investigated crushed basalt aggregates can be classified as nonreactive aggregates. Their expansions of less than $0.1 \%$ at 16 days are indicative of innocuous 
behavior in most cases. Further, the aggregates of higher percentage of $\mathrm{SiO}_{2}$ showed more expansion.

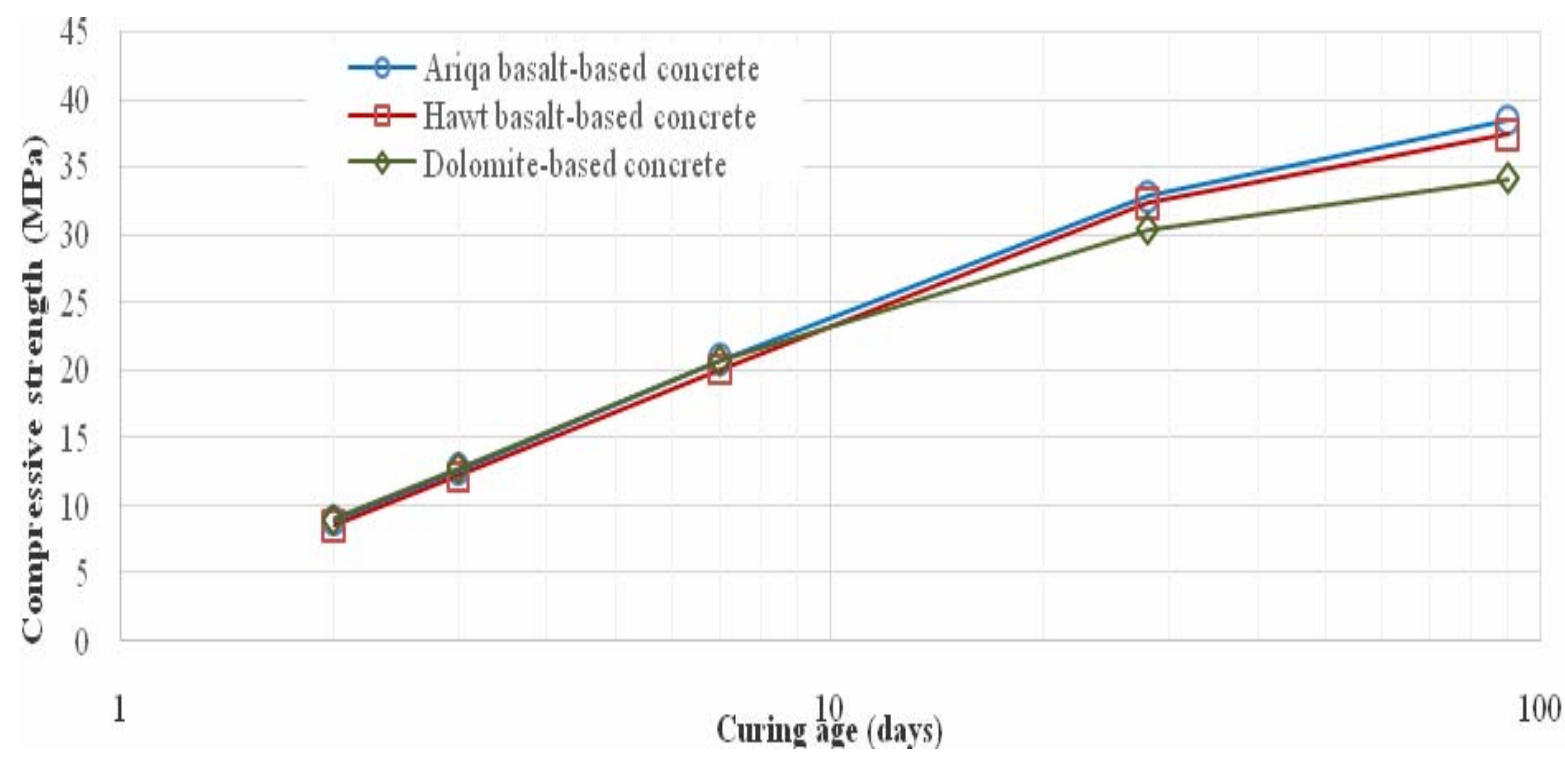

Figure 4: Strength development of concrete specimens with curing ages

Weight changes of concrete samples after 90 days of exposure to $10 \% \mathrm{NaOH}$ are plotted in Fig.7. All the investigated aggregates gained some weight. Weight gains for specimens of these aggregates varies from 0.2 to $1.0 \%$ of their initial weights. This could be attributed to the non-leaching of lime in the alkaline environment and the non-susceptibility of these aggregates when exposed to a highly alkaline environment. In addition, no evidence of alkalisilica gel or network of ASR cracks covering the concrete surface were noted. Further, the compressive strengths of concrete samples containing the investigated basalt were not affected by this exposure, and no decrease in strength was observed.

Further, inspection of concrete structures of 10 years old or older could be a reliable mean to determine potential ASR susceptibility of basalt aggregate [23]. The environments which are most conducive to deleterious reactivity are moist, damp and wet-dry environments [23]. Two structures for each basalt were inspected. The first one was concrete water tank constructed in the beginning of 2000 while the other was juice production plant which is about 12 years old. Reviewing the project records, showed that the alkali-level of the cement used in the inspected concrete was more than 1\%. No map cracking, evidence of movement due expansion or deposits of alkali-silica gel were observed along scaled concrete surfaces. 


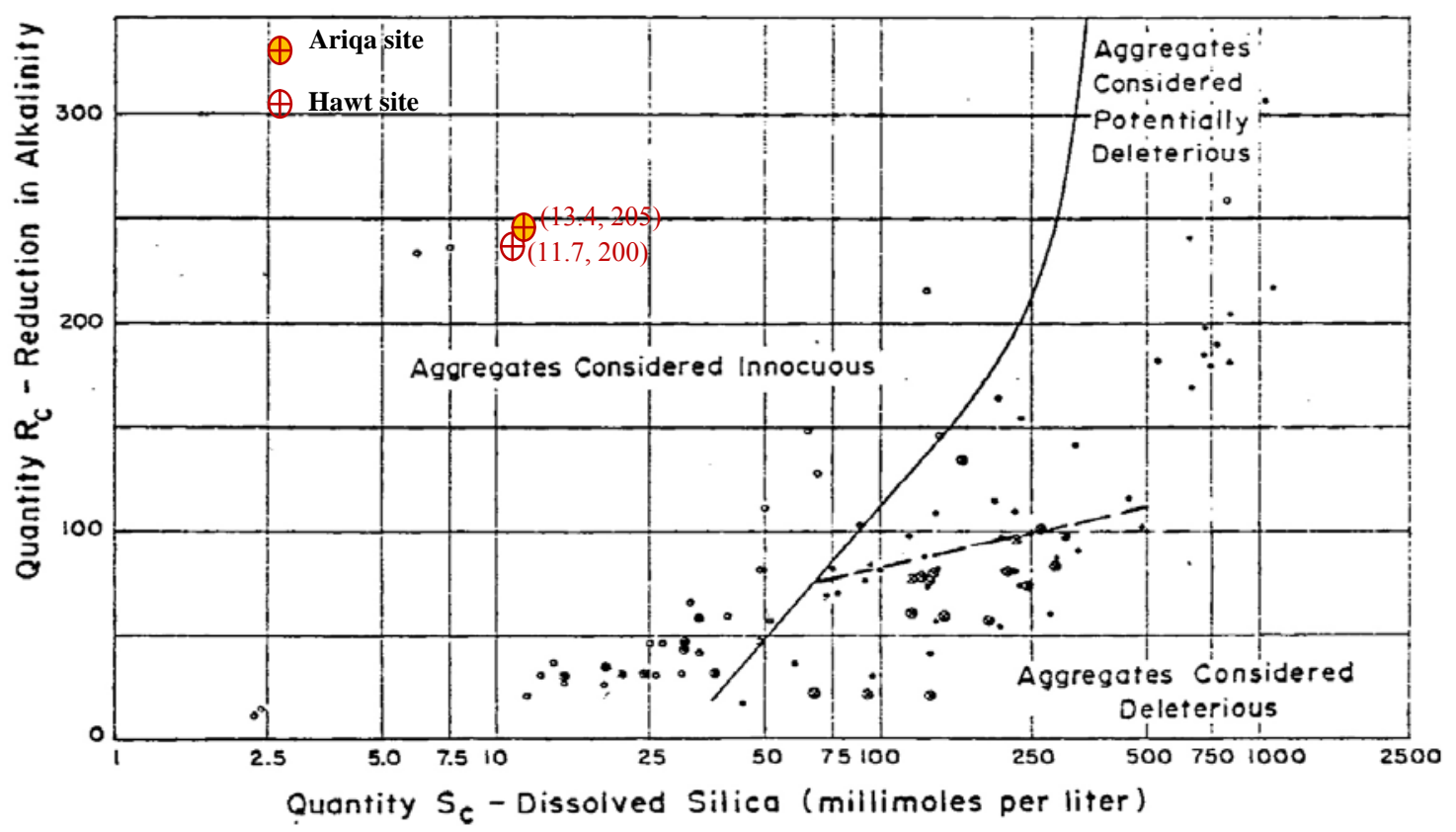

Figure 5: The dissolved silica and the corresponding reduction of alkalinity for each of basalt aggregate

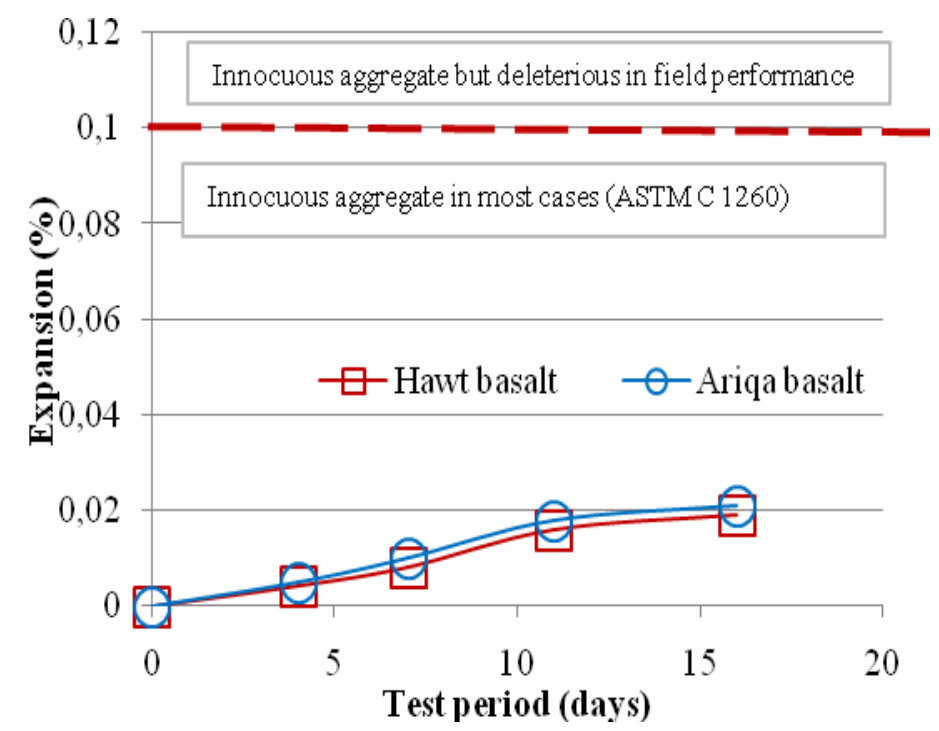

a)

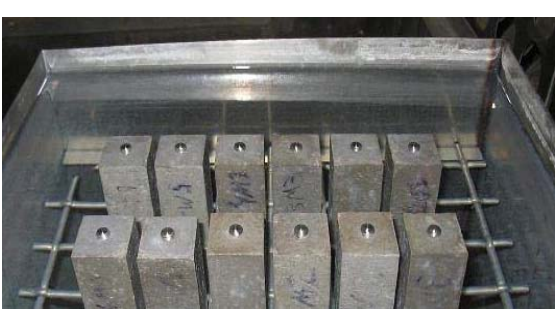

b)

Figure 6: a) Length Measurements of mortar bars subjected to the test specified in ASTM C1260. b) View of mortar bars placed in the container 


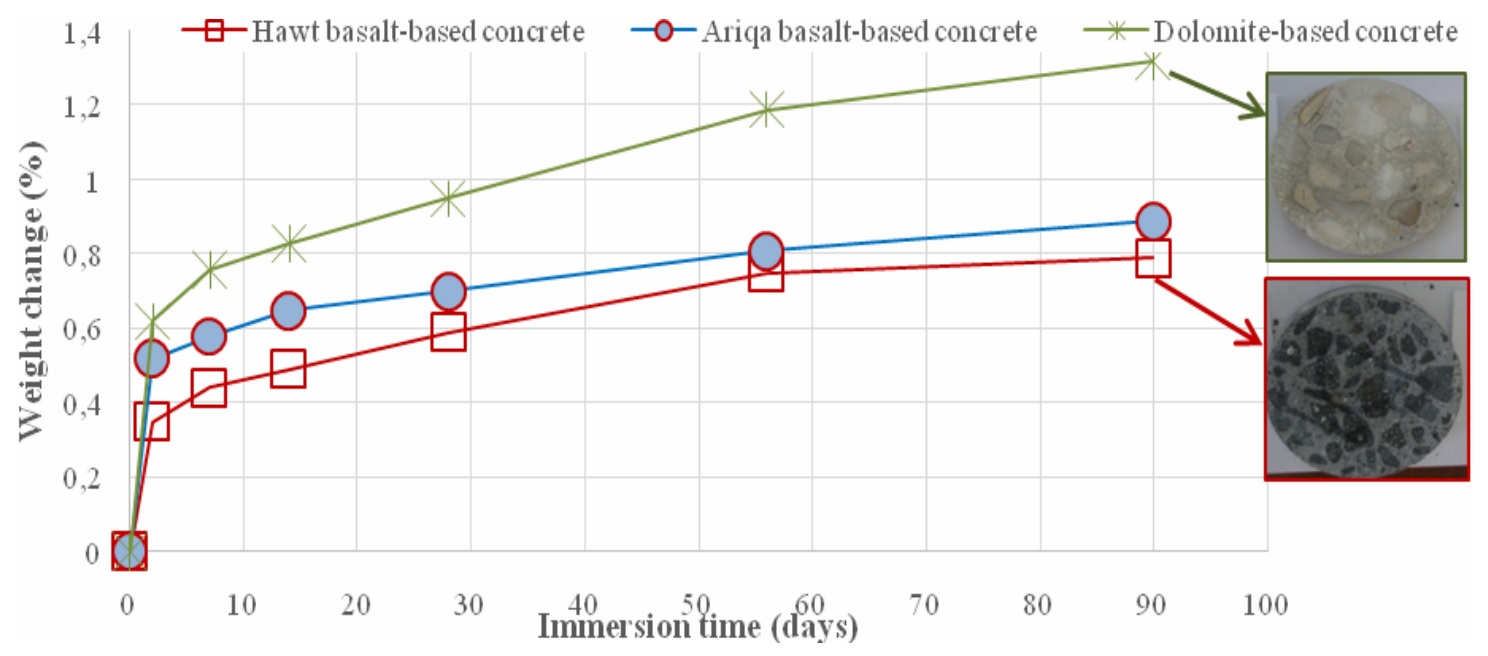

Figure 7: Weight changes with times of BBC \& DBC specimens exposed to $10 \% \mathrm{NaOH}$ solution.

\section{Conclusion}

Based on the experimental results reported in the paper, the following conclusions can be drawn:

- Since the properties of Al-Swaida'a basalt meet the specification limits, basalt can be used in the PC concrete mixes.

- The physical and mechanical properties of both crushed basalt aggregates were superior to those of crushed dolomite aggregates. However, the bulk specific gravity of the former was more than that of the latter aggregates.

- The results from the dissolved silica in the chemical test method matched the behavior shown in the accelerated test method (ASTM C1260) for the samples tested.

- Based on the test results, both of basaltic aggregates were not susceptible to alkali attack. They did not produce a deleterious reaction and a decrease in compressive strength when used in a highly alkaline environment. So, not all basaltic rocks will react deleteriously in the concrete. However, appropriate performance testing of another aggregate source is recommended to confirm alkali-silica reactivity.

\section{Acknowledgements}

The authors gratefully acknowledge the technical and financial support of this research from the Order of Syrian Engineers. Thanks are also expressed to Prof. Tamer al-Hajeh, Vice-President of AIU for his help in some steps. 


\section{References}

[1] Ibrahim A.; Faisal S. \& Jamil N.(2009). Use of basalt in asphalt concrete mixes. Construction and Building Materials, 23(1), 498-506. DOI:10.1016/j.conbuildmat.2007.10.026.

[2] Goodman, RE. (1993). Engineering Geology: Rock in Engineering Construction. Wiley, New York.

[3] Tasong WS., Lynsdale CJ.\& Cripps JC. (1998). Aggregate-cement paste interface: II. Influence of aggregate physical properties. Cement and Concrete Research, 28 (10), 1453- 1465. DOI: 10.1016/S0008-8846(98)00126-4.

[4] Ozturan T. \& veCecen C. (1997). Effect of coarse aggregate type on mechanical properties of concretes with different strengths. Cement and Concrete Research, 27 (2), 165- 170.DOI: 10.1016/S0008-8846(97)00006-9.

[5] Ahmad S. \& Alghamdi SA. (2012). A study on effect of coarse aggregate type on concrete performance, Arab J Sci Eng., 37(7),1777-1786. DOI: 10.1007/s13369-012-0282-6.

[6] The General Establishment of Geology and Mineral Resources in Syria (2011). A Guide for mineral resources (in Arabic).

[7] The General Establishemnt of Geology and Mineral Resources in Syria (2007). Official document nr. (3207/T/9) dated 21.11.2007.(in Arabic).

[8] Duchensne J. \& Bertron A. (2013). Leaching of cementitious materials by pure water and strong acids $\left(\mathrm{HCl}\right.$ and $\left.\mathrm{HNO}_{3}\right)$. In Alexander M., Bertron A., De Belie, Performance of cement-based materials in aggressive aqueous environments; state-of-the-Art Report, RILEM TC 211-PAE.

[9] Neville AM. (2011). Properties of concrete, fifth edition. Pearson Education.

[10] Zivica V. \& Bajza A. (2001). Acid attack of cement based materials-A review, Part1. Principle of acidic attack. Construction and Building materials, 15, 331-340.DOI: 10.1016/S09500618(01)0012-5.

[11] Alexander M. \& Mindess S. (2005). Aggregates in concrete. Taylor \& Francis.

[12] Hobbs DW. (2008). Alkali-silica reaction in concrete. In Bensted J. \& Barnes P. (Eds.), Structure and performance of cements, second edition. Taylor \& Francis, pp.:265-281.

[13] Smith MR.\& Collis L. (2001). Aggregates: Sand, gravel and crushed rock aggregates for construction purposes, third edition, The Geological Society London.

[14] Kurdowski W. (2014). Cement and concrete chemistry. Springer.

[15] Wakizaka Y. (2000). Alkali-silica reactivity of Japanese rocks. Engineering Geology, 56(12),211-221. DOI: 10.1016/S0013-7952(99)00144-1.

[16] Dyer T. (2014). Concrete durability. Taylor \& Francis Group.

[17] Korkanc M. \& Tugrul A. (2005). Evaluation of selected basalts from the point of alkali-silica reactivity. Cement and Concrete Research, 35, 505-512. DOI:10.1016/j.cemconres.2004.06.013. 